\title{
Biomass Production and Water: A Brief Review of Recent Research
}

\author{
Gregory F. McIsaac
}

Published online: 20 September 2014

(C) Springer International Publishing AG 2014

\begin{abstract}
The Energy Independence and Security Act (EISA) mandated an increase in the production of liquid fuels from renewable sources, including corn, soybeans, and perennial crops. Expanded corn production poses a risk to water quality, and expanded production of perennial crops for cellulosic ethanol may have positive effects on water quality as well as positive or negative impacts on water quantity. Nitrate contamination from corn production is greatest in regions with subsurface drainage systems. Sediment and phosphorus contamination are more likely to come from sloping soils. The risks to water quality can be reduced by conservation practices, such as planting winter cover crops, but the costs of implementing these practices represent a barrier to adoption when there is little or no benefit to the farm owner or operator. The magnitude of these impacts appears to be highly variable and there is a need for more empirical work to improve simulation models to quantify the impacts in different physiographic settings and at a range of scales.
\end{abstract}

Keywords Water · Biofuel · Ethanol - Maize - Miscanthus · Switchgrass $\cdot$ Nitrate $\cdot$ Tile drainage $\cdot$ Land use $\cdot$ Hydrology . Cover crops

\section{Introduction}

The Energy Independence and Security Act (EISA) mandated an increase in the production of liquid fuels from renewable sources. First-generation biofuels are those based on existing technologies such as ethanol from corn starch and biodiesel

\section{G. F. McIsaac $(\bowtie)$}

Department of Natural Resources and Environmental Sciences, University of Illinois at Urbana-Champaign, 1102 South Goodwin Avenue, Urbana, IL 61821, USA

e-mail: gmcisaac@illinois.edu from soybean oil. Second-generation biofuels are based on conversion of cellulosic materials (e.g., corn stover, perennial grasses, or wood) into liquid fuels which generally require additional research and development. Land use changes to produce biofuel feedstocks and the facilities to convert the feedstocks into liquid fuels could have significant impacts on water quality and quantity at different scales.

USEPA (the US Environmental Protection Agency) presented its first triennial report to Congress on environmental impacts of EISA which reviewed the scientific literature and concluded that the largest impacts on water are likely to come from feedstock production, with expanded corn production posing risks to water quality [1]. Nitrate contamination of surface waters from corn production tends to be greatest in regions with subsurface drainage systems. Sediment and phosphorus contamination are more likely on sloping soils. Production of perennial crops for cellulosic ethanol could provide some benefit to water quality compared to corn production, but the greater water use of perennials poses some risk to water quantity. Wu et al. presented a more recent review of water resource impacts of biofuels with an international scope [2]. The review presented here seeks to complement these earlier reviews by focusing on research specific to regions within the USA published since 2011. Some overlap with the previous reviews was needed to provide context for the studies discussed below.

\section{Conventional Ethanol Production from Corn Starch}

To date, the largest consequence of EISA has been increased production of ethanol from corn starch, which has increased the demand and price of corn, and expanded the area planted in corn and aggregate fertilizer use. In the Corn Belt region of midwestern USA, some land that had been in a corn-soybean rotation has been shifted to a corn-corn-soybean rotation. Corn requires relatively large amounts of nitrogen $(\mathrm{N})$ 
fertilizer, which is subject to leaching losses, especially in areas with artificial subsurface drainage (tiles) or sandy soils $[3,4]$. Nitrate transport down the Mississippi River was unusually large in 2013 because the drought of 2012 reduced N uptake by the corn crop, leaving greater than normal amounts of residual fertilizer $\mathrm{N}$ in the soil, which was subsequently leached into streams and rivers by abnormally large spring rains.

In the western Corn Belt and Great Plains, large expanses of grasslands have been converted to corn-soybean production [5]. Conversion of grasslands to annual row crops often leads to greater rates of surface runoff, soil erosion, and transport of sediment and phosphorus to surface waters.

\section{Process Water Versus Production Water Demand}

The impacts on water quantity and water quality of producing corn and other crops for biofuel feedstock tend to be much larger than impacts from processing $[2,6]$. Approximately two-thirds of the groundwater withdrawn from US aquifers in 2005 was used for irrigation, including irrigation of corn for biofuel. In 2008, approximately $18 \%$ of the corn grain produced in the USA came from irrigated acres [7]. The amount of water used to irrigate corn in Nebraska, for instance, was about 200 times the amount used in converting the corn to ethanol [8]. Water demand for irrigated corn in the USA has been projected to increase due to climate change [9].

Conventional facilities for producing ethanol from corn starch require about 3-4 gallons of high-quality water per gallon of ethanol produced, which is mostly drawn from deep aquifers [8]. If conventional ethanol production expands to 20 billion gallons per year by 2016 as projected, this would require $60-80$ billion gallons of water per year, which is less than $0.3 \%$ of the 29 trillion gallons of groundwater withdrawn from freshwater aquifers in the USA in 2005 [10]. While this represents a trivial increase in groundwater withdrawal nationally, the impacts will be concentrated where these processing plants are located. A moderately sized conventional facility producing 100 million gallons of ethanol per year will require about 300 million gallons of high-quality water per year, which is similar to the water needs of a municipality of 5,000 people [11]. In many jurisdictions, groundwater withdrawals are subject to local or state permitting and wastewater discharges from processing facilities will be regulated as point sources under the Clean Water Act. While water use by processing facilities is likely to be a concern of local importance in facility siting decisions, the technology and institutions for addressing water supply and water quality impacts of these facilities are reasonably well-established. On the other hand, the regulatory frameworks for addressing water quality and surface water quantity impacts of crop production are less well-developed and more difficult to implement.

\section{Advanced or Second-Generation Biofuel}

In addition to mandating an overall level of renewable fuel production, EISA mandates an increasing percentage of renewable fuel be derived from cellulosic material, such as wood, perennial grasses, or crop residues (leaves and stems, also known as stover). Initial efforts to produce cellulosic ethanol have focused on using stover from corn, wheat, or sugar cane, in part because of their uniformity and availability and the availability of harvesting equipment.

Prior to the 1980s, traditional management of annual crops involved inversion or moldboard plowing of stover into the soil followed by additional tillage to control weeds. The stover contributed to soil organic matter, water holding capacity, and soil fertility, but plowing and intensive tillage left the soil surface exposed to the erosive forces of wind and water. With the adoption of herbicides to control weeds, the intensity of tillage has declined and leaving stover on top of the soil in a field after harvesting the grain has provided some protection for the soil against erosion. Removal of significant quantities of stover for biofuel could lead to increases in erosion and reduction of soil carbon.

Loss of soil cover and carbon from harvesting crop stover may be mitigated by planting winter cover crops in the late summer or fall [12]. While the cover crops help retain soil and reduce surface runoff where they are grown, weather conditions [e.g., dry fall (autumn) or early frost] frequently prevent successful establishment. Where successfully planted, cover crops can reduce nitrate leaching, but any economic benefit to growers, if any, depends on the characteristics of the site and the practices employed.

Based on a large plot study in Iowa, Daigh et al. reported significantly less drainage from continuous corn harvested for both grain and stover ( $50 \%$ removal) than from corn grown in rotation with soybeans and harvested only for grain. Including a winter cover crop with the continuous corn reduced the average peak flow rate during drainage events, which could reduce flood risks if adopted on a large scale [13].

Many studies have shown that winter cover crops can reduce nutrient losses from cropland in many settings, but the percentage reduction has varied widely. An extensive literature review by the Iowa Department of Agriculture and Land Stewardship, Iowa Department of Natural Resources, and Iowa State University College of Agriculture and Life Sciences (2013) indicated that the impact of adding a winter rye cover crop ranged from increasing nitrate losses by $10 \%$ to reducing them by $94 \%$, with an average reduction of $31 \%$ [14]. Phosphorus losses with a winter cover crop in the rotation have been reported to increase by as much as $39 \%$ and to decrease by as much as $68 \%$, with an average reduction of $29 \%$. In a modeling study, Dale et al. (2010) reported nitrate reductions from including a winter cover crop in annual crop rotation ranging from 65 to $75 \%$ [12]. These reductions are 
toward the upper end of the range of previously reported reductions and deserve closer scrutiny and empirical confirmation. Economic costs and hydrologic impacts of the cover crops were not studied or reported by Dale et al. [12].

\section{Perennial Feedstocks}

Perennial grasses for biofuel feedstock will likely produce less $\mathrm{N}$ and phosphorus losses to surface waters than corn [15-17], but due to greater evapotranspiration, these are also likely reduce the quantity of water raining downstream $[18,19]$. This could be beneficial in reducing flood flows, and it could also be detrimental if and where it reduces water availability during critical low-flow periods. The highest yielding perennial crops with the greatest water use efficiency would be able to satisfy biomass demand with the least land and water footprints, but if production becomes highly concentrated in an area, then the water resource impacts would be similarly concentrated.

Based on simulations with the Soil Water Assessment Tool (SWAT) model, Schilling et al. (2008) estimated that converting extensive areas of corn-soybean to perennial grass in central Iowa would result in about $25 \%$ less water yield [20]. Sediment and phosphorus yields were reduced by as much as $97 \%$ but nitrate losses were reduced by only $10 \%$ if switchgrass was grown with $157 \mathrm{~kg} \mathrm{~N} / \mathrm{ha}$ of fertilizer applied. In a subsequent study, Schilling et al. (2014) used the SWAT model to estimate a substantial reduction in flood risk from converting corn-soybean to switchgrass in central Iowa.

Jager et al. (2014) used a suite of models, including SWAT, to forecast future land cover and hydrologic changes in the Arkansas-Red-White River Basin in the south central USA with and without cellulosic biofuel production [21]. Switchgrass was simulated to be the dominant cellulosic biofuel crop, covering $5.1 \%$ of the basin by 2030 . Reductions in sediment, phosphorus, and $\mathrm{N}$ loads were simulated compared with a simulation without cellulosic biofuel production. Water yield also decreased a median of $21.8 \%$ across the 173 sub-basins they simulated.

The perennial grass Miscanthus $x$ giganteus has also been the subject of considerable research because it is more productive and appears to require less $\mathrm{N}$ fertilizer than switchgrass [15, 22]. Its high productivity involves greater water use, which is partly due to the lack of seed production $[18,23]$. Late in the summer, $M . x$ giganteus continues to invest energy in producing new leaves while switchgrass and other grasses invest considerable energy in producing seed rather than leaves. Under current climatic conditions in central Illinois, Le et al. (2011) estimated evapotranspiration (ET) by M. $x$ giganteus to b $208 \mathrm{~mm}$ year $^{-1}$ greater than corn, while switchgrass is $118 \mathrm{~mm}$ year $^{-1}$ greater than corn, which in this region could reduce annual water yields by approximately 60 and $30 \%$, respectively [23]. Future climate scenarios with higher temperatures and less rainfall may reduce water yields even further according to the simulations of Le et al. (2011) [23]. However, these estimates may be subject to revision as newer varieties are developed and as more is learned about $M . x$ giganteus, which is a relatively new crop [24]. Aurendale et al. (2014) reported that 10-year average M. x giganteus yields were about $20 \%$ lower than reported in previous studies that had focused on yields 3-5 years after planting. Although water use was not measured, ET is generally coupled with biomass production, and therefore long-term average water use of M.x giganteus may be less than suggested by the earlier studies. Higher water use efficiency of $M . x$ giganteus could potentially offset negative consequences of higher water use, depending on the particular setting and the proportion of land converted to this crop [25, 26].

Evapotranspiration contributes water vapor to the atmosphere and it is possible that some of the greater ET from perennial biofuel crops will be recycled locally as greater precipitation. Khanal et al. (2013) used a regional climate model to examine potential changes in precipitation in the USA from extensive switchgrass production primarily in Oklahoma and Kansas [27]. Precipitation increased in some areas of Oklahoma and Kansas, but the greatest increases in precipitation occurred in the eastern and northeastern USA, where increased precipitation can cause increased flooding and soil erosion.

\section{Limitations of Simulation Models}

Watershed scale simulation models, such as SWAT, used to estimate the impacts of biofuels are based on extensive bodies of research but are still subject to a variety of limitations. Wu et al. (2014) identified several weaknesses in modeling perennial biomass crops with SWAT: the database includes only one variety of switchgrass, and crop canopy parameters are fixed throughout the simulation period rather than responding to variations in weather [2]. Schilling et al. (2014) identified tile drainage as an aspect of SWAT requiring further research and development in order to simulate flood flows with greater certainty [14]. Tile drainage is also important for simulating movement of nitrate from field to surface waters $[3,4]$. Increased ET from perennial crops may contribute to increased rainfall [27] but several models used to evaluate changes in stream flow, such as Agro-IBIS (agricultural version of the Integrated Biosphere Simulator model) [25] and SWAT, do not incorporate atmospheric processes to estimate this effect.

In addition to model structure, modeling studies are limited by the availability of relevant input data. The locations and extent of tile drain systems is generally unknown and can only be estimated from soil properties. Soil properties are highly variable and digitally available at only a very coarse 
resolution. Soil microbial processes of biological $\mathrm{N}$ fixation and organic matter mineralization and denitrification are very difficult to measure and can only be estimated at large scales with considerable uncertainty. Fertilizer applications are often estimated from surveys or sales data, but the range and distribution of application rates and timing of application are poorly known.

To address some of these limitations, model parameters are usually selected or 'calibrated' so that the model output fits a time series of past watershed observations and then the calibrated model is used to simulate alternative futures. There are usually a variety of parameter combinations that can fit the model output to the observations, but often only one set of parameters is selected and it is unclear how alternative calibration parameters influence simulation results.

Despite these limitations, simulation studies are generally consistent with results found in empirical studies conducted at smaller scales and/or over shorter time periods. Uncertainties in scaling up need to be recognized, and there is a need for large-scale verification of modeling results.

\section{Summary and Conclusions}

Research published in recent years on the water resource implications of biofuels is consistent with USEPA's 2011 Report to Congress which concluded that the largest impacts on water are likely to come from feedstock production, with expanded corn production posing risks to water quality, and expanded production of perennial crops for cellulosic ethanol posing some risk to water quantity [28]. The water quality risks will depend on the hydrologic setting of the corn production. Nitrate contamination tends to be greatest in regions with subsurface drainage systems. Sediment and phosphorus contamination are more serious in regions with sloping soils. The risks to water quality can be reduced by conservation practices, such as planting winter cover crops, but the costs of implementing these practices represent a barrier to adoption when there is little or no benefit to the farm owner or operator.

The potential impacts of perennial crops on water quantity have received relatively little attention. A few studies have reported reductions in annual water yield from converting land from annual crops to perennial crops, but these are not useful for estimating reductions of flood peaks or low flows. These impacts will vary by location, and the modeling tools used to estimate that variation are in need of improvement. Improving the models will require empirical studies to better quantify how new crops, crop varieties and practices alter water fluxes and water quality under a wide range of environmental conditions.

Finally, there is some need to investigate regulatory and institutional arrangements that could facilitate balancing the interests of producers of biofuel feedstocks and those who would be impacted by conversion of land to biofuel production.

\section{Compliance with Ethics Guidelines}

Conflict of Interest Gregory F. McIsaac declares no conflict of interest.

\section{References}

1. U.S. Environmental Protection Agency. Biofuels and the Environment: First Triennial Report to Congress. Office of Research and Development, National Center for Environmental Assessment, Washington, DC; EPA/600/R-10/183F. 2011. http:// cfpub.epa.gov/ncea/biofuels/recordisplay.cfm?deid=235881.

2. Wu M, Zhang Z, Chiu Y. Life-cycle water quantity and water quality implications of biofuels. Curr Sustain Renew Energy Rep. 2014;1:310. doi:10.1007/s40518-013-0001-2.

3. David MB, Drinkwater LE, McIsaac GF. Sources of nitrate yields in the Mississippi River basin. J Environ Qual. 2010;39:1657-67.

4. McIsaac GF, $\mathrm{Hu} \mathrm{X}$. Net $\mathrm{N}$ input and riverine $\mathrm{N}$ export from Illinois agricultural watersheds with and without extensive tile drainage. Biogeochemistry. 2004;70:251-71.

5. Wright CK, Wimberly MC. Recent land use change in the western corn belt threatens grasslands and wetlands. Proc Natl Acad Sci U S A. $2013 ; 110: 4134-9$.

6. Fingerman KR, Torn M, Kammen D, O’Hare M. Accounting for the water impacts of ethanol production. Environ Res Lett. 2010;5: 014020. doi:10.1088/1748-9326/5/1/014020.

7. USDA (US Department of Agriculture). 2007 Census of Agriculture Farm and Ranch Irrigation Survey (2008). Volume 3, Special Studies, Part 1. 2009. http://www.agcensus.usda.gov/Publications/2007/ Online_Highlights/Farm_and_Ranch_Irrigation_Survey/fris08.pdf.

8. NRC (National Research Council). Water implications of biofuels production in the United States. Washington: The National Academies Press; 2008.

9. Dominguez-Faus R, Folberth C, Liu J, Myers Jaffe A, Alvarez PJ. Climate Change Would Increase the Water Intensity of Irrigated Corn Ethanol. Environ Sci Technol. 2013;47:6030-7.

10. Kenny JF, Barber NL, Hutson SS, Linsey KS, Lovelace JK, Maupin MA. Estimated use of water in the United States in 2005. U.S. Geological Survey Circular 1344, 52 p. 2009. http://pubs.usgs.gov/ circ/1344/.

11. IOM (Institute of Medicine). The nexus of biofuels, climate change, and human health: workshop summary. Washington: The National Academies Press; 2014.

12. Dale B, Bals B, Kim S, Eranki P. Biofuels done right: land efficient animal feeds enable large environmental and energy benefits. Environ Sci Technol. 2010;44:8385-9.

13. Daigh AL, Zhou X, Helmers MJ, Pederson CH, Ewing R, Horton R. Subsurface drainage flow and soil water dynamics of reconstructed prairies and corn rotations for biofuel production. Vadose Zone J. 2014. doi:10.2136/vzj2013.10.0177.

14. Iowa Nutrient Reduction Strategy: a science and technology-based framework to assess and reduce nutrients to Iowa waters and the Gulf of Mexico. Ames: Iowa Department of Agriculture and Land Stewardship, Iowa Department of Natural Resources, and Iowa State University College of Agriculture and Life Sciences. 2013.

15. Ng TL, Eheart JW, Cai X, Miguez F. Modeling miscanthus in SWAT to simulate its water quality effects as a bioenergy crop. Environ Sci Technol. 2010;44:7138-44.

16. Ng T, Eheart W, Cai X, Braden J, Czapar G. Farmer decisions and stream nitrate load in response to price incentives for 
second-generation bioenergy crop cultivation, and carbon and nitrogen fertilizer reduction. J Water Resour Plan Manag. 2014;140:112-20.

17. Smith CM, David MB, Mitchell CA, Masters MD, AndersonTeixeira KJ, Bernacchi CJ, et al. Reduced nitrogen losses after conversion of row crop agriculture to perennial biofuel crops. J Environ Qual. 2013;42:219-28.

18. McIsaac GF, David MB, Mitchell CA. Miscanthus and switchgrass production in central Illinois: impacts on hydrology and inorganic nitrogen leaching. J Environ Qual. 2010;39:1790-9.

19. Schilling KE, Gassman PW, Kling C, Campbell T, Jha M, Wolter C. The potential for agricultural land use change to reduce flood risk in a large Midwestern watershed, U.S.A. Hydrol Process. 2014;28:3314 25 .

20. Schilling KE, Jha MK, Zhang Y, Gassman PW, Wolter CF. Impact of land use and land cover change on the water balance of a large agricultural watershed: historical effects and future directions. Water Resour Res. 2008;44:W00A09. doi:10.1029/ 2007WR006644.

21. Jager HI, Baskaran LM, Schweizer PE, Turhollow A, Brandt $\mathrm{CC}$, Srinivasan R. Forecasting changes in water quality in rivers associated with growing biofuels in the ArkansasWhite-Red river drainage, USA. GCB Bioenergy. 2014. doi: 10.1111/gcbb.12169.
22. Heaton EA, Dohleman FG, Miguez F, Juvik JA, Lozovaya V, Widholm J, et al. Miscanthus: a promising biomass crop. Adv Bot Res. 2010;56:75-137.

23. Le PVV, Kumar P, Drewry DT. Implications for the hydrologic cycle under climate change due to the expansion of bioenergy crops in the Midwestern United States. Proc Natl Acad Sci U S A. 2011;108: 15085-90.

24. Robertson AD, Davies CA, Smith P, Dondini M, McNamara NP. Modelling the carbon cycle of Miscanthus plantations: existing models and the potential for their improvement. Global Chang Biol Bioenergy. 2014. doi:10.1111/gcbb.12144.

25. VanLoocke A, Twine TE, Zeri M, Bernacchi CJ. A regional comparison of water use efficiency for miscanthus, switchgrass and maize. Agric For Meteorol. 2012;164:82-95.

26. Zeri M, Hussain MZ, Anderson-Teixeira KJ, DeLucia EH, Bernacchi CJ. Water use efficiency of perennial and annual bioenergy crops in central Illinois. J Geophys Res Biogeosci. 2013;118:581-9.

27. Khanal S, Anex RP, Anderson CJ, Herzmann DE, Jha MK. Implications of biofuel policy-driven land cover change for rainfall erosivity and soil erosion in the United States. Global Chang Biol Bioenergy. 2013. doi:10.1111/gcbb.12050.

28. NRC (National Research Council). Renewable fuel standard: Potential economic and environmental effects of U.S. biofuel policy. Washington: The National Academies Press; 2011. 